\title{
Rare location of Universal tumor
}

\author{
Shankar Bastakoti ${ }^{1}$, Amar Shrestha ${ }^{2}$, Dej Kumar Gautam ${ }^{2}$, Ranjan Raj Bhatta ${ }^{1}$ \\ ${ }^{1}$ Department of Pathology, ${ }^{2}$ ENT and Head and Neck unit, Department of surgical oncology, BP Koirala Memorial \\ Cancer Hospital
}

\begin{abstract}
:
Lipomas are one of the most common benign mesenchymal tumor in human. Lipoma occurring in the tongue is rare as tongue has paucity of normal adipose tissue. Here we present an unusual case of lipoma presented in the tongue, and removal of which comforted patient by regaining of the functional task of tongue. Fifty two year's old Muslim women presented with painless swelling on right lateral border of tongue for 5 years for which excision was done and histopathology evaluation was performed. The histopathology was consistent with the diagnosis of Lingual Lipoma. Existence of lipoma in the tongue is very rare, which can be managed by simple excision. Histopathology is the gold standard in the diagnosis.
\end{abstract}

Keywords: lipoma, tongue, adipocytes

\section{Introduction}

Lipomas are one of the most common benign mesenchymal tumor in human. It is composed of mature adipocytes. ${ }^{1}$ Lipoma occurring in the tongue is rare as tongue has paucity of normal adipose tissue. It usually affects middle-aged individuals and may slowly enlarge causing difficulties in speech and mastication. ${ }^{2}$ Generally these are well circumscribed, noninvasive and have a low recurrence rate except for the intramuscular variant where tumor are encroaching the muscle bundle. Post treatment recurrence rate is low and conservative surgical management is the treatment of choice. ${ }^{3}$

Interestingly, the metabolism of the lipoma differs from that of the normal adipose tissue. It has been found that the fat component of lipoma is not used for energy production during starvation phase as happens with normal adipose tissue., ${ }^{4,5}$ Here we present an unusual case presented in rare location i.e tongue, removal of which comforted the patient by regaining of functional task of the tongue.

\section{Case report}

Fifty two year's old Muslim women residing in Terai region of Nepal presented with painless swelling on right lateral border of tongue for 5 years with clinical suspicion of hemangioma or lipoma. Due to discomfort in functional activities and cosmetic reason excision of the mass was done and histopathology evaluation was performed. On gross examination (Fig.1) well circumscribed thin capsulated nodular growth was noted with cut section revealing pale yellow, homogeneous and smooth surface. The lesion measured $2.5 \times 2.3 \mathrm{~cm}$. Microscopic examination revealed fibrous capsule with enclosed multiple lobulated sections of mature adipocytes of relatively uniform size and shape(Fig. 2, 3). There was no evidence of hyperchromasia, pleomorphism, or multinucleation of adipocytes and no evidence of lipoblasts. In addition, no hemorrhage or areas of necrosis.

The histopathology was consistent with the diagnosis of Lingual Lipoma.

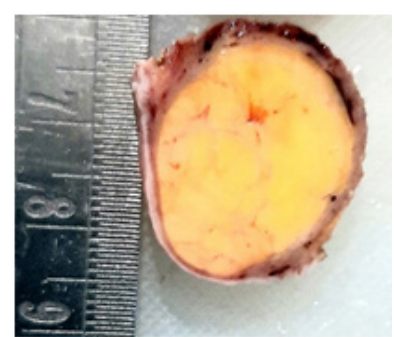

Figure 1: ross Cut section: Capsulated Yellowish lesion

Dr Shankar Bastakoti, Department of Pathology, BP Koirala Memorial Cancer Hospital 


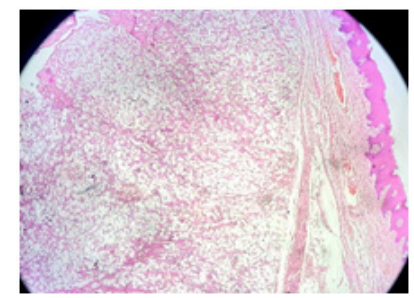

Figure 2: Outer squamous lining underneath fibrous capsule enclosing the sheets and lobule of adipocytes (H\&E, 10x)

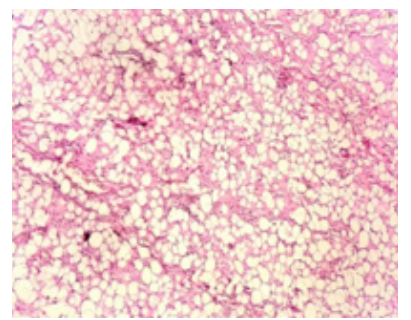

Figure 3: Mature adipocytes in sheets.(H\&E,40x)

\section{Discussion:}

Lipoma can occur anywhere on the human body thus it is termed as "universal tumor" or "ubiquitous tumor". ${ }^{6}$ Roux et al in 1848, gave the first description of an intra-oral lipoma and he described to it as a "yellow epulis". 7 Lipoma of the oral cavity is rare and different prevalence has been reported in different studies ranging from 0.5 to $5 \%$. Intra-orally, it commonly occurs on buccal mucosa, floor of the mouth, lips and muco-buccal fold and tongue. ${ }^{1,2,5,8,9}$

Lipomas are usually seen in patients above 40 years of age without any gender predilection, but some studies reported male predilection, ${ }^{8}$ and our case is 52 years female. Most lipoma are slow-growing, painless, soft, circumscribed, and associated with submucosal nodules with either a sessile or a pedunculated base. ${ }^{3}$ Our case also presented as similar feature of nodular mass lesion.

Histopathologically, lipomas are classified as simple lipoma or variants such as fibrolipoma, spindle cell lipoma, intramuscular or infiltrating lipoma, angiolipoma, salivary gland lipoma (sialolipoma), pleomorphic lipoma, myxoid and atypical lipomas. ${ }^{9}$ Long standing lipomas of face and oral cavities can lead to oro-facial deformities, macro-glossia, atrophy of tongue musculature, dental abnormalities (including masticatory difficulties and interference with movements of the tongue leading to airway and speech problems). In addition, secondary trauma may cause large lipomas to ulcerate and bleeding might be the presentation. ${ }^{10,11}$

Surgical resection is the mainstay of treatment.
Well-encapsulated lipomas, including classical lipomas, are easily managed without recurrence. Regarding non-encapsulated or infiltrating lipomas, it is recommended to excise them with a cuff of surrounding normal tissue to prevent recurrence, but it is vital to conserve surrounding structures. ${ }^{11,12}$

\section{Conclusion:}

Lipomas are common benign mesenchymal tumors, but their existence in the oral cavity especially tongue is very rare, which can be managed by simple excision with rare complications. Histopathology is the gold standard in the diagnosis.

\section{References:}

1. Varma BR, Kumar KS, Verghese RS, et al. BMJ Case Rep 2020; 13:e232485. doi:10.1136/bcr-2019- 232485

2. Magadum D, Sanadi A, Agrawal JM, et al. Classic tongue lipoma: a common tumour at a rare site. BMJ Case Rep 2013;2013:bcr2012007987

3. Dehghani N, Razmara F, Padeganeh T, et al. Oral lipoma: case report and review of literature. Clin Case Rep 2019;7:809-15

4. Chandak S, Pandilwar PK, Chandak T, Mundhada R. Huge lipoma of tongue. Contemp Clin Dent. 2012 Oct; 3(4):507-9. doi: 10.4103/0976-237X.107457. PMID: 23633822; PMCID: PMC3636840

5. Wells HG. The fat metabolism of lipomas. Arch intern med (chic). 1912; X (4):297-304. doi:10.1001/ archinte.1912.00060220002001

6. Thakur M, Reddy Kundoor VK, Maloth KN, Nayanala VA. Intraoral lipoma at an unusual site: A rare presentation. J Dent Allied Sci 2017; 6:98-100.

7. Rapidis AD. Lipoma of the oral cavity. Int J Oral Surg 1982;11:30-5

8. Furlong MA, FanburgSmith JC, Childers EL. Lipoma of the oral and maxillofacial region: Site and subclassification of 125 cases. Oral Surg Oral Med Oral Pathol Oral Radiol Endod 2004;98:441-50

9. Neville BW, Damm DD, Allen CM, Bouquot JE. Oral and Maxillofacial Pathology; 2nd edition: Elsevier publication; 2004

10. Magadum D, Sanadi A, Agrawal JM and Agrawai MS: Classic tongue lipoma: A common tumour at a rare site. BMJ Case Rep 30: 1-4, 2013.

11. Lu, S., Zheng, J., Wu, H., Li, T., Dong, G., Wang, Y., \& Yang, P. (2016). Tongue lipoma in an older male: A case report and literature review of patients with tongue lipoma reported in China. Oncology Letters, 11, 419422. https://doi.org/10.3892/ol.2015.3865

12. Fregnani ER, Pires FR, Falzoni R, Lopes MA and Vargas PA: Lipomas of the oral cavity: Clinical findings, histological classification and proliferative activity of 46 cases. Int J Oral Maxillofac Surg 32: 49-53, 2003 